financially by grants to the Institute of Biochemistry, Uppsala, from the Swedish Technical Research Council and a grant from the U.S. Department of Army through its European Office under contract number $D A-91-591-E U C-1025$, and by grants to the Institute of Hygiene and Bacteriology, Uppsala, from the Swedish Medical Research Council.

\section{PER-Åke Albertsson} Lennart Philipson

Institute of Biochemistry and

Institute of Hygiene and Bacteriology, University of Uppsala.

${ }^{1}$ Albertsson, P. A., Nature, 182, 709 (1958).

2 Albertsson, P. A., and Nyns, Ed. J., Nature, 184, 1465 (1959).

${ }^{3}$ Albertsson, P. A., and Nyns, Ed. J. (in preparation).

Albertsson, P. A., and Frick, G., Biochim. Biophys. Acta (in the press).

${ }^{5}$ Frick, G., and Albertsson, P. A., Nature, 183, 1070 (1959).

'Wesslén, T., Albertsson, P. A., and Philipson, L., Archiv Virus forsch. (in the press).

'Philipson, L., Albertsson, P. A., and Frick, G. (in preparation).

'Albertsson, P. A., Biochim. Biophys. Acta, 27, 378 (1958).

- Albertsson, P. A., Hanzon, V., and Toschi, G., J. Ultrastructure Res., 2, 366 (1959).

\section{Presence of Metanephrine and Normetanephrine in Normal Human Urine}

IN 1957, Axelrod reported that epmepnrme and norepinephrine were $\mathrm{O}$-methylated at the $\mathrm{C}-3$ position, giving metanephrine (3-O-methylepinephrine) and normetanephrine (3-O-methylnorepinephrine), respectively. in the rat ${ }^{1}$; in addition, he found that these compounds were normally excreted in rat urine ${ }^{2}$. The excretion of normetanephrine in the urine of humans with pheochromocytoma has also been reported $^{3}$. More recently, the importance of the pathway for 3-O-methylation of epinephrine has been confirmed in man*. This report concerns the identification of metanephrine and normetanephrine of endogenous origin in the urine of normal human males.

Preliminary attempts to isolate these compounds were not successful because free metanephrine and normetanephrine are present in small amounts and are labile. Since the major portion of these metabolites was found to be excreted in a conjugated form, the conjugates were isolated by chromatography on ion-exchange resin ${ }^{5}$, freed by hydrolysis, and identified.

A tracer amount (less than $0 \cdot 018 \mu M$ ) of a conjugate of tritiated metanephrine sulphate (3-O-methyl-7- ${ }^{3} \mathrm{H}$ epinephrine-4-O-sulphate), prepared biosynthetically, was added to $100 \mathrm{ml}$. portions of five individual urine specimens from normal human males; this amount of ${ }^{3} \mathrm{H}$-metanephrine sulphate was too small to give spots on the chromatograms. These specimens were filtered and chromatographed on $1 \times 10 \mathrm{~cm}$. columns of 'Dowex 1', acetate form. Distilled water $(200 \mathrm{ml}$.) and $3.100 \mathrm{ml}$. portions of $0.2 \mathrm{~N}$ acetic acid were passed through each of the columns; the effluent was collected in $100 \mathrm{ml}$. fractions.

The radioactivity was eluted in the $0.2 \mathrm{~N}$ acetic acid fractions ; these fractions from each individual column were combined and lyophilized. The resulting residues were redissolved in water. No substances in these urine extracts gave the phenolic reactions of metanephrine or normetanephrine prior to hydrolysis. Aliquots from the concentrated solutions of urine extracts were hydrolysed by heating with $1 \mathrm{~N}$ hydrochloric acid in a water bath at $37^{\circ} \mathrm{C}$. for $48 \mathrm{hr}$.
Approximately 2 per cent of each of the hydrolysed extracts was chromatographed on Whatman No. l filter paper in four different solvent systems: (a) $n$-butanol/glacial acetic acid/water $(80: 20: 20)$; (b) iso-propanol/7 $N$ ammonia $(80: 20)$; (c) benzene/ propionic acid/water $(40: 40: 20)$, and $(d) n$-butanol/ iso-propanol/15 $N$ ammonia $(80: 30: 20)$. The urinary metabolites gave colour reactions with diazotized sulphanilic acid, diazotized para-nitroaniline and N-2,6-trichloro- $p$-quinoneimine that were identical with authentic metanephrine and normetanephrine.

The colour reactions, migration on paper chromatograms, and behaviour on ion exchange resins indicate that endogenous metanephrine and normetanephrine are excreted by normal human males in the absence of pheochromocytoma or of administration of exogenous epinephrine. The metabolites are excreted mainly as conjugates; detailed evidence to be presented elsewhere indicates that these are sulphoconjugates in humans. Although much valuable information has been obtained by analysis of urinary epinephrine and norepinephrine, these compounds represent only a small percentage of the total endogenous production. Since urinary metanephrine and normetanephrine, free and conjugated, and 3methoxy-4-hydroxymandelic acid represent the major portion of exogenous, and presumably endogenous, epinephrine and norepinephrine $e^{1,2,4}$, analysis of these O-methylated metabolites appears to offer promise of a more valid estimate of endogenous production of these important hormones.

We wish to thank Dr. Julius Axelrod and Dr. Seymour S. Kety for many helpful discussions during the course of this study.

Elwood H. LaBrosse

JAY D. MANN

Laboratory of Clinical Science,

National Institute of Mental Health,

National Institutes of Health, Bethesda, Maryland.

${ }^{1}$ Axelrod, J., Science, 126, 400 (1957).

Axelrod, J., Senoh, S., and Witkop, S., J. Biol. Chem., 233, 697 (1958).

${ }^{3}$ LaBrosse, E. H., Axelrod, J., and Sjoerdsma, A., Fed. Proc., 17, 386 (1958)

L LaBrosse, E. H., Axelrod, J., and Kety, S., Science, 128, 593 (1958). ${ }^{5}$ Kirchner, N., Goodall, Mc.C., and Rosen, L., Proc. Soc. Exp. Biol. Med., 98, 627 (1958)

\section{ANIMAL PHYSIOLOGY}

\section{Reserpine and the Levels of Serotonin and Norepinephrine in the Brain}

As an outgrowth of the results obtained in a number of laboratories, there appeared an explanation for the effect of reserpine which was based on the existence of reduced levels of serotonin and norepinephrine in the brain at a time when no reserpine was detectable ${ }^{1}$. Most of these methods suffered from the experimental use of massive doses of reserpine, which rendered the animal quite immobile. Subsequent work, using much lower doses of reserpine labelled with tritium and carbon-14, demonstrated that reserpine was present in the brains of guinea pigs at an unchanging concentration over the entire period of observable pharmacological effects ${ }^{2}$. From these investigations it was not possible to demonstrate any correlation between the intensity of effect of the drug and its concentration in the brain. With these 